\title{
Utilization of Postpartum Family Planning Services between Six and Twelve Months of Delivery at Ntchisi District Hospital, Malawi
}

\author{
Chrissy Bwazi ${ }^{1}$, Alfred Maluwa ${ }^{2}$, Angela Chimwaza ${ }^{2}$, Mercy Pindani2 $^{2}$ \\ ${ }^{1}$ Ntchisi District Hospital, Ntchisi, Malawi \\ ${ }^{2}$ Kamuzu College of Nursing, University of Malawi, Lilongwe, Malawi \\ Email: ${ }^{*}$ aomaluwa@kcn.unima.mw
}

Received 10 May 2014; revised 22 June 2014; accepted 11 July 2014

Copyright (C) 2014 by authors and Scientific Research Publishing Inc.

This work is licensed under the Creative Commons Attribution International License (CC BY). http://creativecommons.org/licenses/by/4.0/

(c) () Open Access

\begin{abstract}
This study examined factors that determine utilization of postpartum family planning services at Ntchisi District Hospital in Malawi. The study design was descriptive and utilized quantitative methods of data collection and analysis. A random sample of 383 postpartum women was interviewed using a structured questionnaire. Data were analysed using SPSS version 16.0. Chi-square tests were used to establish relationships between utilization of Post Partum Family Planning services and demographic variables. Knowledge about family planning services was almost universal at $94.3 \%$ among the women. About $75 \%$ of the women were using the contraceptives within the first year after delivery however they started taking the contraceptives after they had already resumed sex. There was a significant association $(P<0.05)$ between utilization of post partum family planning services and the following: clarity of family planning information given, level of education, period for resuming sex, husband's approval of family planning method, counselling on fertility intention, duration of lactation amenorrhoea, maternal age and parity. There is therefore a need to promote these factors to increase uptake of postpartum services.
\end{abstract}

\section{Keywords}

Postpartum Family Planning, Contraception, Social Networks, Beliefs, Past Behaviour and Habits, Lactation Amenorrhoea, Postpartum Sexual Activity

\section{Introduction}

The first year after a woman has given birth is crucial for use of contraceptives to prevent unwanted pregnancy ${ }^{*}$ Corresponding author.

How to cite this paper: Bwazi, C., Maluwa, A., Chimwaza, A. and Pindani, M. (2014) Utilization of Postpartum Family Planning Services between Six and Twelve Months of Delivery at Ntchisi District Hospital, Malawi. Health, 6, 1724-1737. 
[1]. Many women, however, do not realize that they are at a risk for pregnancy during this period [1] [2]. Consequently, contraceptive use by women during this period is low, resulting to unintended pregnancies and unwanted childbearing [3]. About 80 million unintended pregnancies worldwide are accounted for low utilization of contraceptives during the postpartum period [4]. In addition, 30\% of all births in sub-Saharan Africa are due to low utilization of family planning (FP) services [3]. Worldwide, the unmet need for FP among postpartum women is estimated at $40 \%$ [3]. In Malawi, only $26 \%$ of postpartum women use FP methods during this period with unmet need of $70 \%$ [1]. If properly utilized postpartum family planning (PPFP) is one of the best interventions to reduce maternal and neonatal morbidity and mortality [5] because two thirds of maternal and neonatal mortalities occur during the postnatal period [6].

It is recommended that for a normal pregnancy and live infant, a woman should wait for a period of two years before attempting to become pregnant [1] [7] [8]. In Malawi, this recommendation is supported by the Sexual and Reproductive Health Policy and guidelines [4]. Consequently, it is mandatory for all people to have free access to FP information and services in Malawi. In addition, women are encouraged to space their pregnancies either by using modern or natural FP methods.

In Malawi, knowledge of FP services is almost universal at 98.5\% among both men and women, however utilization of postpartum family planning (PPFP) services is poor [9]-[13]. There are many studies that have been conducted on PPFP world-wide, however studies on the factors that promote utilization of PPFP services in Malawi are limited. Therefore this study was conducted to determine the factors that promote/inhibit utilization of PPFP services in Malawi.

\section{Study Objective}

This study was conducted to investigate factors that are associated with the utilization of PPFP services by women between six and twelve months of delivery in Malawi.

\section{Methodology}

\subsection{Design}

The study design was descriptive and followed quantitative research paradigm to determine factors that are associated with utilization of PPFP services by women between six and twelve months of delivery. A structured questionnaire was used to collect data on a random sample of 383 postpartum women who met the inclusion criteria and consented to participate in the study.

\subsection{Setting}

The study was conducted at a Well Baby Clinic within the maternal and child health (MCH) department of Ntchisi District hospital from $1^{\text {st }}$ to $31^{\text {st }}$ July, 2011. Ntchisi district is located in the Central Region of Malawi. According to unpublished data at the facility, some 10,390 women delivered at the facility in 2011.

\subsection{Sample}

The study recruited 383 postpartum women that were randomly selected from those that met the inclusion criteria of the study. The sample size was determined using the formula $n=\left(Z^{2} P(1-P)\right) / e^{2}$ [14]. In which $n$ is the sample size, $Z$ is the value of a normally distributed variable which for a $95 \%$ confidence interval takes the value of 1.96; $\mathrm{P}$ is the proportion of under one children in the district which was 0.05 and e is the allowable error which for this study was set at 0.05 .

\subsection{Inclusion and Exclusion Criteria}

The study targeted women who had given birth the past 6 to 12 months, regardless of parity, religion, culture, education and maternal age. The study however excluded women that had children older than 12 months or younger than 6 months; Furthermore women that had aborted recently, or those who had tubal ligation and total abdominal hysterectomy; or those who had a still birth and/or neonatal deaths with the previous pregnancy were excluded from the study. 


\subsection{Data Collection}

A structured questionnaire (Appendix) was used to collect data. The questionnaire was orally administered using in-depth face to face interview by the senior author who is a state registered nurse and was assisted by research assistants who were nurse midwife technicians. The 3 research assistants were trained by the senior author prior to the data collection exercise. To ensure reliability and validity of the data collection instrument, pretesting was done on five (5) postpartum mothers at Khuwi Health centre within the district. The components of the questionnaire were demographic data, knowledge of mothers about PPFP services, beliefs related to PPFP services, influence of social networks and past experience related to FP method use. The interviews on average lasted about twenty minutes. All questionnaires were checked for completeness to ensure that valid data was collected at the end of each data collection day.

\subsection{Data Analysis}

Data were analyzed using SPSS version 16.0. Descriptive statistics in the form of frequencies and percentages were computed for the variables in the data set. Chi-Square tests were used to investigate the associations between utilization of postpartum family planning services and the demographic variables (age, education level, parity and marital status). Other variables that were investigated were; clarity of FP information, period of resuming sexual activity, husband's approval of the FP method, husband's assistance, counselling on fertility and duration of lactation amenorrhoea. The test level of significance was $5 \%$.

\subsection{Ethical Considerations}

The study was approved by Kamuzu College of Nursing (KCN) Research and Publications Committee (RPC) and the College of Medicine Research and Ethics Committee (COMREC). The District Health Officer for Ntchisi District Hospital gave an approval to conduct the research in his catchment area. Privacy and confidentiality, respect of clients' rights and fair treatment of study participants were strictly observed during data collection process including minimizing harm and discomfort. Informed consent was obtained from each participant before administration of a questionnaire.

\section{Results}

\subsection{Demographic Characteristics}

The demographic characteristic of the participants are summarized in Table 1. The age range of the respondents was 16 to 49 years with mean of 25 years. There was a significant association between current use of PPFP services and age of the participant $\left(\chi^{2}=7.836 ; \mathrm{df}=3 ; \mathrm{P}=0.050\right)$. The parity of the women ranged from 1 to 11 with $23 \%(n=44)$ having 5 or more children. There was a significant association between current utilization of PPFP services and parity $\left(\chi^{2}=15.624 ; \mathrm{df}=2 ; \mathrm{P}=0.000\right)$. About $9 \%(\mathrm{n}=18)$ had older children aged $1-2$ years. Few participants (only $6 \%, n=22$ ) wanted to have another child within the next 2 years and $43 \%, n=164$ wanted a child in the next 5 years. The majority $(82 \%, n=314)$ of the women discussed with their spouses about the number of children they planned to have as a couple. There was a significant association between current use of PPFP services and holding of FP discussions with the husband $\left(\chi^{2}=8.038 ; \mathrm{df}=2 ; \mathrm{P}=0.000\right)$. Thirty eight percent $(n=145)$ wanted to have 5 or more children while $33 \%, n=126$ of the respondents' husbands wanted more than 5 children. The desired number of children was significantly associated with current use of PPFP services $\left(\chi^{2}=9.802 ; \mathrm{df}=3 ; \mathrm{P}=0.020\right)$. About $25 \%, \mathrm{n}=96$ had secondary education and there was a significant association $\left(\chi^{2}=10.905 ; \mathrm{df}=2 ; \mathrm{P}=0.004\right)$ between utilization of PPFP services and level of education.

\subsection{Knowledge of Postpartum Family Planning Services by Respondents}

Most respondents $(94.3 \%, \mathrm{n}=361)$ were able to mention one or more FP methods. Of all respondents, $24.4 \%, \mathrm{n}$ = 93 knew about lactation amenorrhoea as a method of family planning. Depot medroxy progesterone acetate (DMPA) was mentioned by most $(94.3 \%, \mathrm{n}=361)$ of the respondents, condoms by $74.6 \%, \mathrm{n}=286$ then implants which was mentioned by $72.5 \%, n=278$ of the participants. Only a few $(1.6 \%, n=6)$ knew the emergency contraception (EC), Standard Days Method (SDM) was known by $2.6 \%, \mathrm{n}=10$ of the participants and finally natural family planning method (NFP) was mentioned by $4.7 \%, n=18$ of the participants. There was a 
Table 1. Demographic characteristics of respondents $(\mathrm{N}=193)$.

\begin{tabular}{|c|c|c|}
\hline Characteristics & Frequency & Percentage \\
\hline \multicolumn{3}{|c|}{ Age of respondents in years } \\
\hline $15-19$ & 21 & 10.9 \\
\hline $20-24$ & 79 & 40.9 \\
\hline $25-34$ & 78 & 40.4 \\
\hline 35 and above & 15 & 7.8 \\
\hline \multicolumn{3}{|l|}{ Marital status } \\
\hline Single & 10 & 5.2 \\
\hline Married & 180 & 93.3 \\
\hline Divorced & 3 & 1.6 \\
\hline \multicolumn{3}{|l|}{ Education level } \\
\hline No education & 19 & 9.8 \\
\hline Primary & 126 & 65.3 \\
\hline Secondary & 48 & 24.9 \\
\hline \multicolumn{3}{|l|}{ Parity } \\
\hline $1-4$ & 149 & 77.2 \\
\hline $5-8$ & 41 & 21.2 \\
\hline 9 and $\geq$ & 3 & 1.6 \\
\hline \multicolumn{3}{|l|}{ Abortions } \\
\hline No abortion & 150 & 77.7 \\
\hline $1-2$ & 41 & 21.2 \\
\hline $3-4$ & 2 & 1.0 \\
\hline \multicolumn{3}{|l|}{ Age of last child } \\
\hline No child & 49 & 25.5 \\
\hline $1-2$ yrs & 18 & 9.3 \\
\hline $2-4$ yrs & 68 & 35.2 \\
\hline $5 \mathrm{yrs}$ and $\geq$ & 58 & 30.1 \\
\hline \multicolumn{3}{|c|}{ Period when mothers wanted to give birth to the next child } \\
\hline No child & 11 & 21.2 \\
\hline No plan & 8 & 15.4 \\
\hline$\leq 1 \mathrm{yr}$ & 1 & 1.9 \\
\hline $1-2$ yrs & 6 & 11.6 \\
\hline $2-3$ yrs & 15 & 29.0 \\
\hline $3-4$ yrs & 16 & 30.9 \\
\hline 5 yrs and above & 43 & 83.0 \\
\hline \multicolumn{3}{|c|}{ Total number of children desired by the mothers } \\
\hline Not decided & 5 & 9.7 \\
\hline $1-4$ & 58 & 112.0 \\
\hline $5-8$ & 32 & 61.8 \\
\hline 9 and above & 4 & 7.7 \\
\hline \multicolumn{3}{|c|}{ Number of children desired by husband } \\
\hline Not decided & 19 & 36.7 \\
\hline $1-4$ & 49 & 94.6 \\
\hline $5-8$ & 30 & 57.9 \\
\hline 9 and above & 5 & 9.7 \\
\hline
\end{tabular}

significant association between current use of PPFP services and knowledge of the services $\left(\chi^{2}=26.436\right.$; $\mathrm{df}=1$; $\mathrm{P}=0.000)$.

In general, $74.6 \%, \mathrm{n}=286$ of the women were using contraception during the first year after childbirth. About 
$61 \%, \mathrm{n}=233$ used DMPA. The least known methods were female condom, natural methods and vasectomy as none of the participants mentioned these methods. There was a significant association $\left(\chi^{2}=8.499\right.$; $\mathrm{df}=2$; $\mathrm{P}=$ 0.014) between current utilization of PPFP services and clarity of information given.

\subsection{Source of Knowledge about PPFP Services before and after Delivery}

Seventy four percent $(n=193)$ received the information at the antenatal clinic during pregnancy while $54.4 \%$ ( = 193) got the information from postnatal ward before discharge. No woman mentioned having received information during home education, FP and under five clinics.

\subsection{Postpartum Counselling}

Few women received postpartum counselling. Only $5 \%(n=19)$ of the women received information on transition from LAM to other FP methods while about $10 \%(\mathrm{n}=38)$ had information on fertility return (Figure 1). However, of those who received the information, $66 \%, n=127$ indicated that the information they received was clear. There was a significant association between utilization of PPFP services and counselling on fertility intentions $\left(\chi^{2}=4.967 ; \mathrm{df}=1 ; \mathrm{P}=0.026\right)$.

\subsection{Reasons for Current Non-Use of Contraceptive Methods}

The participants gave various reasons for current none use of contraceptives. About $11.4 \%(n=42)$ of the women were waiting for the return of menses. There were however $5.2 \%, \mathrm{n}=20$ of the participants that were not willing to use the methods, $3 \%, n=11$ were single, $22 \%, n=84$ had young children and were afraid that should the children die, they would take long to conceive, $1.6 \%$ had no knowledge of the services while the same percentage wanted to have bilateral tubal ligation (BTL). Two percent $(n=8)$ had only one child and was afraid of being infertile due to the effects of the contraceptives and $(0.3 \%, n=1)$ respondent had medical restriction.

\subsection{Influence of Beliefs Regarding Family Planning Services}

All respondents belonged to a particular denomination and except for $0.3 \%, \mathrm{n}=1$ of the respondents who was restricted by her tradition to use FP services. However, neither tradition nor religious belief was a hindrance to the use of contraceptives for $99 \%, n=379$ of the participants.

\subsection{Influence of Social Networks on Postpartum Family Planning Services}

Husbands $(40.9 \%, n=153)$ were major opinion makers on issues of reproduction. Only 2.6\% $(n=5)$ respondents were given chances by their spouses to participate in the decision making. There was a significant association $\left(\chi^{2}=32.946 ; \mathrm{df}=2 ; \mathrm{P}=0.000\right)$ between current utilization of PPFP services and husband's approval of the FP method.

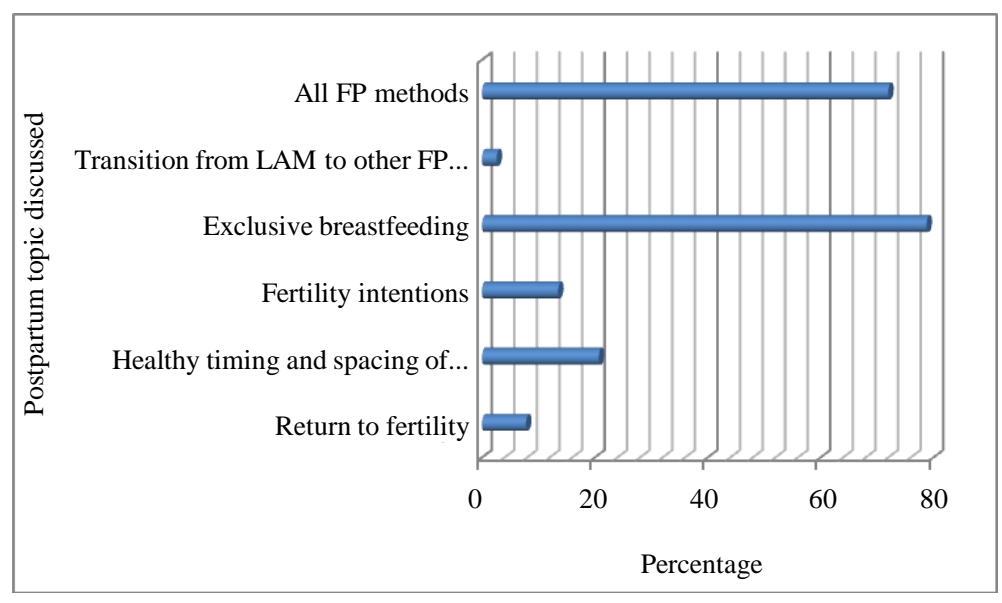

Figure 1. Percentage of mothers who received postpartum counselling. 


\subsection{Assistance Husbands Provide to Show Their Approval of FP Service Utilization}

Husbands assisted the women in form of financial support $(46 \%, n=176)$ and the husbands also reminded the women $(45 \%, n=172)$ about the next appointment dates. The husbands also participated in the FP methods by procuring some contraceptive method such as using the male condom. There were $14 \%, \mathrm{n}=54$ of the husbands who used the male condoms but none had vasectomy. Consequently, there was a significance association $\left(\chi^{2}=\right.$ 33.867; $\mathrm{df}=2$; $\mathrm{P}=0.000$ ) between current utilization of PPFP services and husband's assistance to the postpartum women.

\subsection{Past Behaviour and Habit}

Over half of the respondents $(58.5 \%, \mathrm{n}=224)$ used the FP methods within the past five years. Out of these, $42 \%$, $\mathrm{n}=94$ reported to have experienced problems. Those who reported prolonged vaginal bleeding were $24 \%, \mathrm{n}=$ 54 , seconded by backache $(9.7 \%, n=22)$ then abdominal pains $(7.1 \%, n=16)$. The least scoring problems were leg pains $(2.7 \%, n=6)$ and numbness of body organs $(1.8 \%, n=4)$. These problems were hindrances to current use of the methods. There was a significant association between current utilization of PPFP services and past problems with FP methods $\left(\chi^{2}=14.873\right.$; $\left.\mathrm{df}=2 ; \mathrm{P}=0.001\right)$.

\subsection{Period when Mothers Started Using Contraceptives}

Thirty six percent started using the contraceptive methods when their children were three months of age while 23.8\% started the contraceptives when their children were six months old (Figure 2).

\subsection{Duration of Lactation Amenorrhoea}

Percentage of women who had menses returned by the first 6 months after delivery was $49.7 \%$; by the end of the first year, 76.7\% had their menses returned (Figure 3). There was a significant association between current utilization of PPFP services and duration of lactation amenorrhoea $\left(\chi^{2}=23.238\right.$; $\mathrm{df}=4$; $\left.\mathrm{P}=0.000\right)$.

\subsection{Return to Sexual Activity after Delivery}

Sixty one percent of the participants had resumed sexual activity when their children were 3 months. By the end of the first year of delivery, 90.2\% were sexually active. Only 9.8\% were not yet sexually active (Figure 4). There was a significant association between current use of PPFP services and period of resuming sexual activity $\left(\chi^{2}=28.967 ; \mathrm{df}=2 ; \mathrm{P}=0.000\right)$.

\section{Discussion}

\subsection{Demographic Characteristics}

The results on the age range and gravidity of the respondents had implications on PPFP services. Pregnancies conceived below 18 and above 39 years pose a health risk to both the mother and her infant [2]. The recommended age range for childbearing is 18 - 35 years (MOH, 2009). The significant association between current use of PPFP services and maternal age and parity in this study shows that there was an increase in the level of utilization of the PPFP services with advancement in age and parity of the mothers. These results are supported by the findings of Okech et al., [15] and Newmann et al., [10]. Thus as women became older and with more children there was increased use of FP methods. These results are desirable because too many pregnancies at old age expose women to pregnancy related complications [2].

In this study, FP services were mainly patronized by married women. These results agree with those reported by Okech et al., [15] in Kenya, in which more married women used contraceptive methods than unmarried ones due to frequent episodes of sexual activities among the married women. Other studies have also reported similar results [10]. Therefore more married women used contraceptives to plan their pregnancies and births which was not the case with their single counterparts. The implication is that unmarried women are at risk for unplanned pregnancies and unwanted child bearing due to their less utilization of family planning services.

The findings that women discussed with their husbands regarding the number of children to have in their families are desirable. However, the desire for more children by both the women and husbands meant that such fam- 


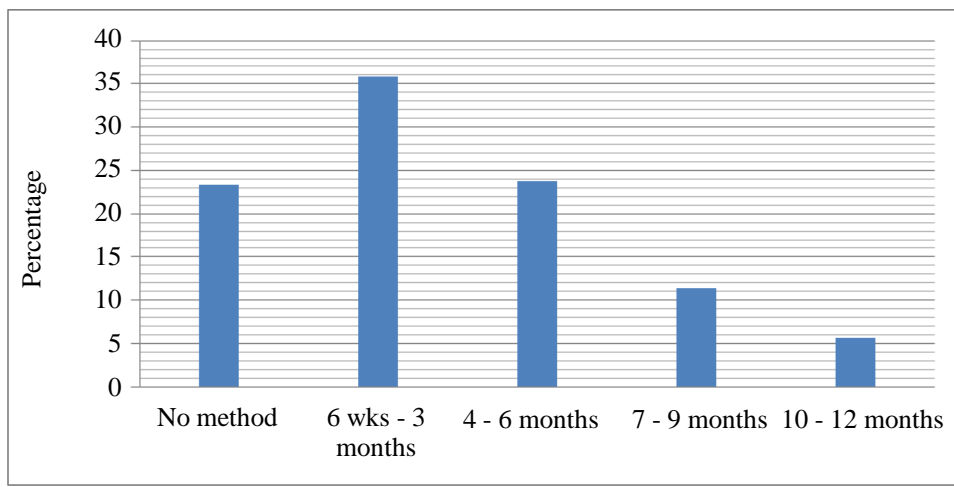

Figure 2. Age of youngest child when mother started using FP method.

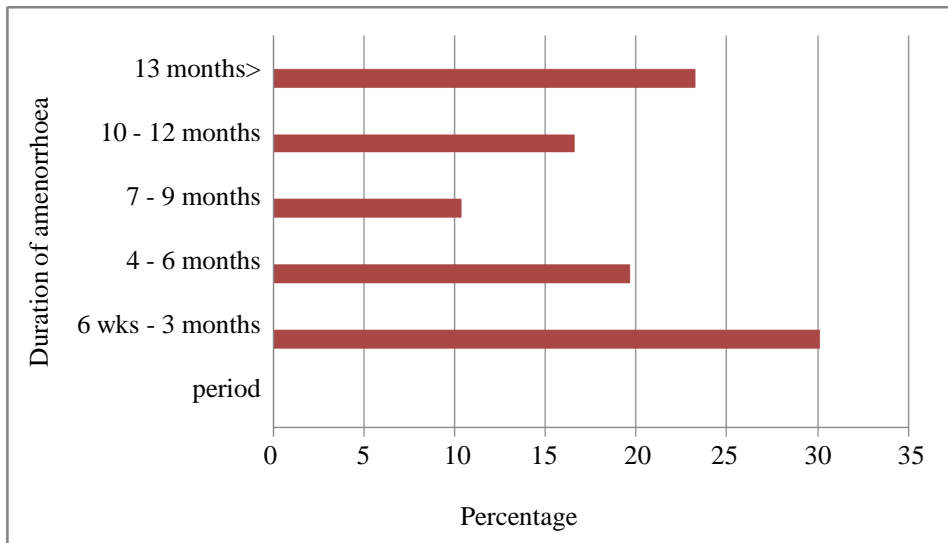

Figure 3. Duration of lactation amenorrhoea after delivery.

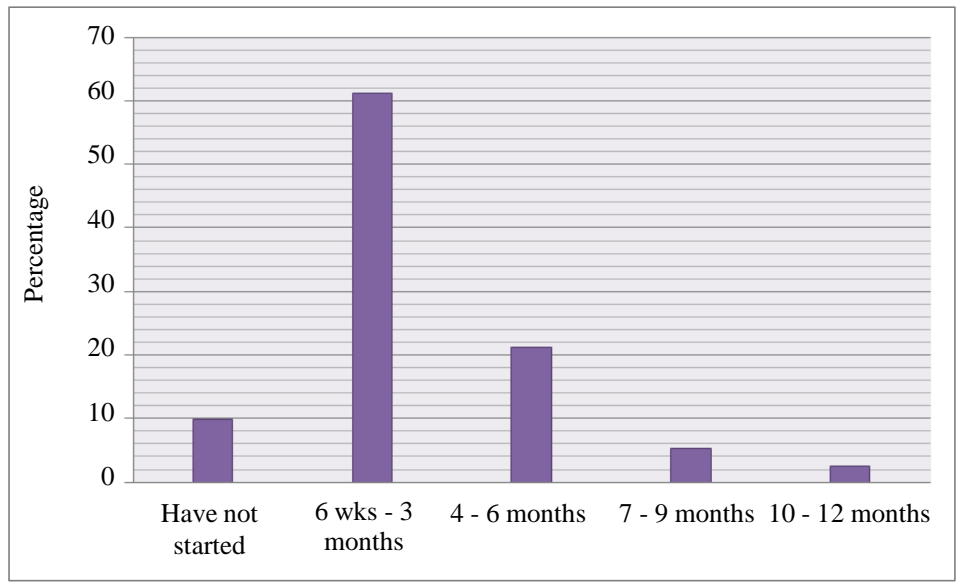

Figure 4. Time when mothers resume sexual activity after delivery.

ilies were not utilizing the family planning services. Similar results were reported by David [16] who reported that the desire for more children by families restricted the use of family planning services. Results show that some families desired more than 5 children. Too many pregnancies expose women to pregnancy and birth related complications. According to $\mathrm{MOH}$ [4], the recommended number of health pregnancies is 4.

\subsection{Knowledge of Postpartum Family Planning Services}

Almost all women in this study had knowledge of contraceptive methods that are available in Malawi. These 
results agree with those reported by NSO [9]. The women were using the contraceptives in the first year after childbirth. However, the result show that most of the women started using the services late. The study further demonstrated that the use of the services was significantly associated with the duration of amenorrhoea and resumption of postpartum sexual activity as the women that resumed sexual activity and those that had their menses returned started using the methods. These results imply that the women were at the risk of unintended and unwanted pregnancies and childbearing as about half of them had menses returned by 6 months. In addition over $80 \%$ resumed sexual activity within 2 or 3 months after birth without using any contraception method. Unintended pregnancies can have negative impact on the women's and neonates' health.

Results show that other women reported to have started being sexually active by 2 weeks after childbirth, thus defeating the purpose of family planning programme as the women could become pregnant before they started using the FP methods and before the return of menses. The results that postpartum women conceive as early as two months of delivery are supported by the findings of Borda et al., [17]. These results may explain the high fertility rate for Ntchisi district which remains at 6.1 according to the MDHS of 2010 [9]. There is therefore a need to create more awareness among the women so that they should first procure an FP method before resumption of sex.

The awareness of natural family planning (NFP) methods including standard days method (SDM) was low in this study. These results agree with the national figures [9]. In addition, there was low awareness among the women regarding emergency contraception (EC) and none of the study participants had used the method. The clinical implication of these results is that the women did not have alternative methods to space their births, thus were exposed to closely spaced and unintended pregnancies. In addition, the women that had unprotected sex did not know how to prevent themselves from having unplanned and unwanted pregnancies.

The results show deficiencies in postpartum counselling as a result very few participants had received education on return to fertility, fertility intentions, HTSP and transition from LAM to other modern methods of contraception. These deficiencies may explain the delays in starting the postpartum contraceptive methods that were observed in this study since the mothers did not understand the importance of early initiation of the methods. Furthermore, the results show that the clarity of the information received was significantly related with the level of education of the women. Thus the best teaching method could have been to intensify the one-on-one contacts to ensure that the women understood the importance of using the services.

The results also demonstrated that family planning education done at antenatal clinic and postnatal ward yields more positive results than the education done elsewhere. This is a crucial finding as it informs the programme managers and providers of maternal and neonatal care (MNH) services. Hence women that do not attend ANC and those who opt for home deliveries are at risk of having closely spaced pregnancies and births. The lack of a significant association between current utilization of PPFP services and religious and or traditional beliefs show that though church norms (especially Catholicism) bar the use of contraceptives, Catholic women were still using contraceptive methods in this study.

\subsection{The Influence of Social Networks}

The study finding illustrated that husbands for some participants were the major decision makers on issues of reproduction. Hence approval or disapproval of the services by the husbands determined the use or non use of the services by the women. These results agree with those that were reported by Duong, et al. [18] Okech et al., [15] Behrman, et al. [19], Haile and Enqueselassie [20], Rubardit and Echevarria [21], Comerasamy et al. [22] and Rakhshani et al. [23]. Therefore there is need to strengthen male involvement during antenatal, family planning and postpartum counselling so that the husbands understand benefits of PPFP services and influence their wives to use the contraceptives. Furthermore, mothers should be encouraged to make informed decisions about contraceptive use as also recommended by Ziyade and Ehlers [24].

\subsection{Past Behaviour and Habits}

The significant association between current use of PPFP services and past problems encountered by the women show that FP service providers should continuously evaluate women on various FP methods. Continuous evaluation of the women will ensure that those facing problems are attended to without delay hence facilitating the development of positive attitude towards the FP services. 


\section{Conclusion}

There is insufficient use of PPFP services at Ntchisi District Hospital. About 25\% of the women do not use the services during the first year of delivery. Furthermore, this proportion was above the national figures. For those who used the services, some started later after they had already resumed sex. Resumption of sex before procuring an FP method puts women at the risk of having closely spaced pregnancies and childbirth. There is a need to remove the barriers that hinder effective use of PPFP services which included the participants' level of education, desire to have many children, inadequate counselling of the mothers, and parity of the women. Influence of subjective norms such as husbands and parents, past experience with the methods, duration of amenorrhoea and time of resumption of postpartum sexual activity were also major determinants for the use of the services. Myths and misconceptions related to the methods like fear of infertility and malformed babies, abortions and twin pregnancies after stopping using the methods also hindered contraceptive use. There is therefore a need to train the women and their husbands in order to dispel the misconceptions and myths regarding FP which in turn will promote more effective PPFP service utilization in the district.

\section{Study Limitation}

The main limitation of the study was that it was conducted on only one health facility and the findings may not represent the whole situation in Malawi although the trends are similar at national level.

\section{Acknowledgements}

This study was conducted as part of the senior author's requirements for the fulfilment of the Degree of Master of Science in Reproductive Health at the Kamuzu College of Nursing of the University of Malawi. The study was funded by USAID and the drafting of the manuscript was funded by Norad through the Maternal Intervention Project in Malawi.

\section{Conflict of Interest}

None of the authors has any conflict of interest for this manuscript to be published in the Health journal.

\section{References}

[1] USAID/ACCESS-FP (2009) Family Planning Needs during the Extended Postpartum Period in Malawi. http://www.k4health.org/sites/default/files/DHS_Malawi.pdf

[2] Ministry of Health (MOH) and Intra Health (2010) Preservice Education Family Planning Reference Guide. MOH, Lilongwe.

[3] WHO \& USAID (2008) Africa’s Health in 2010. Repositioning Family Planning: Guidelines for Advocacy Action.

[4] Ministry of Health (2009) National Sexual and Reproductive Health and Rights (SRHR) Policy.

[5] Mathe, J.K., Kasonia, K.K. and Maliro, A.K. (2011) Barriers to Adoption of Family Planning among Women in Eastern Democratic Republic of Congo. African Journal of Reproductive Health, 15, 69-78.

[6] Matisavich, A. and Santos, M. (2009) Inequalities in Maternal Postnatal Visits among Public and Private Patients. BMC Public Health, 9, 335.

[7] Smith, R., Clifton, D., Gribble, J. and Ashford, L. (2009) Family Planning Saves Lives: Population Reference Bureau. http://www.prb.org/pdf09/familyplanningsaveslives.pdf

[8] Health Communication Partnership Impact (2008) http://www.africomnet.org/commresources/BCCImpact/commImpact_Birth_Spacing_Lessons_learned.pdf

[9] National Statistical Office (2011) Malawi Demographic and Health Survey. Final Report, Zomba.

[10] Newmann, S.J., Goldberg, A.B., Aviles, R., Molina de Perez, O. and Foster-Rosales, A.F. (2005) Predictors of Contraception Knowledge and Use among Postpartum Adolescents in El Salvador. American Journal of Obstetrics and Gynaecology, 192, 1391-1394. http://dx.doi.org/10.1016/j.ajog.2004.12.077

[11] Engin-Ustun, Y., Ustun, Y., Cetin, F., Meydanli, M.M., Kafikasli, A. and Sezgin, B. (2007) Effects of Postpartum Counselling on Postpartum Contraceptive Use. Archives of Gynaecology and Obstetrics, 275, 429-432. http://dx.doi.org/10.1007/s00404-006-0287-z

[12] Ijadunola, K.T., Orji, E.O. and Ajibade, F.O. (2005) Contraceptive Awareness and Use among Sexually Active Breast- 
feeding Mothers in Ile-Ife, Nigeria. East African Medical Journal, 82, 250-256. http://dx.doi.org/10.4314/eamj.v82i5.9315

[13] Kumar, S., Priyadarshni, A., Kant, S., Anand, K. and Yadav, B.K. (2006) Attitude of Women towards Family Planning Methods and Its Use-Study from a Slum of Delhi. Kathmandu University Medical Journal, 3, 259-262.

[14] Lemesho, S., Hosmer, D., Klar, J. and Lwanga, S. (1990) Adequacy of Sample Size in Health Studies. John Wiley \& Sons, New York.

[15] Okech, T.C., Wowire, N.W. and Mburu, T.K. (2011) Contraceptive Use among Women of Reproductive Age in Kenya’s City Slums. International Journal of Business and Social Science, 2, 22-43. http://www.ijbssnet.com

[16] David, O. (2008) Socio-Cultural and Norms Factors Influencing Family Planning Choices among Couples in Ibadan Metropolis, Nigeria. European Journal of Scientific Research, 23, 212-218. http://www.EuroJournals.com/ejsr.htm

[17] Borda, M.R., Winfrey, W. and McKaig, C. (2010) Return to Sexual Activity and Modern Family Planning Use in the Extended Postpartum Period: An Analysis of Findings from Seventeen Countries. African Journal of Reproductive Health, 14, 75-82.

[18] Duong, D.V., Lee, A.H. and Binns, C.W. (2005) Contraception within Six-Month Postpartum in Rural Vietnam: Implications on Family Planning and Maternity Services. European Journal of Contraception and Reproductive Health Care, 10, 111-118. http://dx.doi.org/10.1080/13625180500131527

[19] Berhman, J.R., Kohler, H.P. and Watkins, S.C. (2012) Social Networks and Changes in Contraceptive Use over Time: Evidence from a Longitudinal Study in Rural Kenya. Demography, 39, 713-739. http://dx.doi.org/10.1353/dem.2002.0033

[20] Haile, A. and Enqueselassie, F. (2006) Influence of Women's Autonomy on Couple’s Contraception Use in Jimma Town, Ethiopia. Ethiopian Journal of Health Development, 20, 1-7.

[21] Rubardit, M. and Echevarria, L.O. (2010) Linking Social Norms to Family Planning Behaviours: Baseline Survey for the Results Initiative. http://www.care.org/reprohealth

[22] Comerasamy, H., Read, B., Francis, C. and Gordon, H. (2003) The Acceptability and Use of Contraception: A Prospective study of Somalian Women's Attitude. http://www.ncbi.nlm.nlh.gov/pubmed/12891084

[23] Rakhshan, F., Niknami, S. and Ansari Moghaddam, A.R. (2005) Couple Communication in Family Planning DecisionMaking in Zahedan, Islamic Republic of Iran. Eastern Mediterranean Health Journal, 11, 586-593. http://www.ncbi.nlm.nih.gov/pubmed/16700372

[24] Ziyane, I.Z. and Ehlers, V.J. (2007) Swazi Men’s Contraceptive Knowledge, Attitudes, and Practices. Journal of Transcultural Nursing, 18, 5-11. http://dx.doi.org/10.1177/1043659606294190 


\section{Appendix}

Questionnaire that was administered to participants during the study on utilization of postpartum family planning services between six and twelve months of delivery at Ntchisi district hospital in Malawi.

Respondent's identification number:

Questionnaire administered by:

Date:

PART A: Demographic data. Please tick in the appropriate boxes provided

1. Age of respondent

15 - 19 years

20 - 24 years

25 - 29 years

30 - 34 years

35 - 39 years

40 - 44 years

45 - 49 years

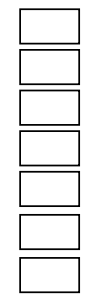

2. Marital status of the respondent

Married

Single

Divorced

Widowed

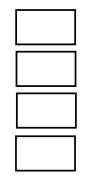

3. Level of education of the respondents

No education

Primary

Secondary

Tertiary

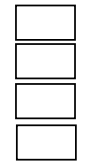

4. Number of pregnancies

5. Number of living children

6. Number of miscarriages/abortions

7. Age of last child

8. When do you intend to have another child?

9. How many children do you intend to have in life?

10. Have you ever discussed with your husband on how many children he is willing to have? YES $\mathrm{NO}$

If yes, how many children does your husband prefer to have?

If NO, why?

PART B TO E: Read the questions below and either tick the appropriate answer or fill in the boxes provided below:

PART B: Knowledge of postpartum family planning (PPFP) services

11. Are you aware of family planning methods that are available at the clinic for postpartum mothers within the first year of delivery?

YES $\square$

NO

If yes, which are these methods?

Lactation Amenorrhoea Method

Progestin Only Pill 
Combined Oral Contraceptive pill Intrauterine Contraceptive Device Injectable contraception (DMPA) Implants

Male condoms

Female condoms

Natural family planning methods

Standard Days Method

Sterilization

Other, please specify

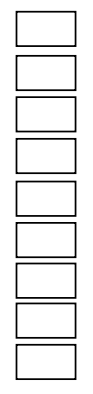

12. Are you currently using any method of contraception since the delivery of your last born child to delay or avoid getting pregnant?

YES

NO

a) If NO,

why?

b) If YES, which method(s) are you currently using?

Lactation Amenorrhoea Method

Progestin Only Pill

Combined Oral Contraceptive pill

Intrauterine Contraceptive Device

Injectable contraception (DMPA)

Implants

Male condoms

Female condoms

Natural family planning methods

Standard Days Method

Sterilization

Other, please specify

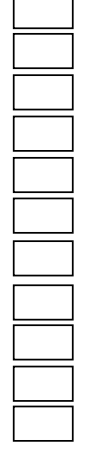

13. Where did you receive education about family planning services before delivery of last child (please check location)

Antenatal clinic

Family planning clinic

During home visits by providers

Other, please specify

14. Where did you receive education about family planning services before delivery of last child (please check location) After delivery of last child (specify location)

Labour and delivery room

Postnatal ward

Expanded programme on immunization visit

Home visit

Well baby visits

Other, specify

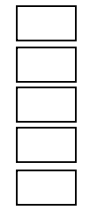


15. What information about family planning was covered during your postpartum counseling? (Check all that apply)

Return to fertility

Fertility intentions

Health timing and spacing of pregnancies

Exclusive breastfeeding

Lactation Amenorrhoea Method

Transition from LAM to other modern methods of family planning

All family planning methods appropriate to fertility regulation

Other, specify

16. Was the information clear?

YES $\square \quad$ NO

PART C: Influence of normative beliefs of the respondent on PPFP services

17. Do you belong to any denomination?

YES

NO

If yes, to which denomination do you belong?

18. Does your denomination allow you to use modern family planning methods to limit your family?

YES

NO

19. Does your traditional culture allow you to use family planning services?

YES

NO

20. Do people in your village use modern methods of family planning?

YES

NO

If "YES", which methods are the most preferred methods in your village?

PART D: Subjective norms' influence on PPFP services

21. Who influences your decisions about family planning practice?

Uncle

Friends

Parents

In-law

Other, please specify

22. Does your husband support you in issues related to family planning services?

YES

NO

If "no", skip to question 12.

23. How best does your husband assist you regarding the use of family planning services?

Supporting through provision of transport

Reminding on dates of appointment

Gives items or finances

Use of condoms (both male and female condoms)

Any other (specify)

24. Whose opinion is important in your family concerning issues of reproduction?

PART E: Past experience and time of starting PPFP services

25. Have you ever used any modern method of contraception within the past five (5) years?

YES

$\mathrm{NO}$

If NO, why? 
If yes, what method(s) of contraception did you use?

26. Did you experience any problem(s) with the method(s)?

YES

NO

If "YES", what was the problem(s)?

27. At what age of the last child did you start using the family planning method above?

6 weeks to 3 months

4 to 6 months

7 to 9 months

10 to 12 months

Other (please specify)

28. For how long do you have lactational amenorrhoea after you have given birth?

6 weeks to 3 months

4 to 6 months

7 to 9 months

10 to 12 months

Other (please specify)

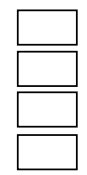

29. Have you resumed sexual activity since the birth of your child?

YES

NO

30. At what age of your child did you resume sexual intercourse?

6 weeks - 3 months

4 - 6 months

7 - 9 months

10 - 12 months

More than 12 months

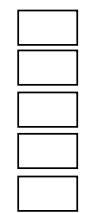


Scientific Research Publishing (SCIRP) is one of the largest Open Access journal publishers. It is currently publishing more than 200 open access, online, peer-reviewed journals covering a wide range of academic disciplines. SCIRP serves the worldwide academic communities and contributes to the progress and application of science with its publication.

Other selected journals from SCIRP are listed as below. Submit your manuscript to us via either submit@scirp.org or Online Submission Portal.
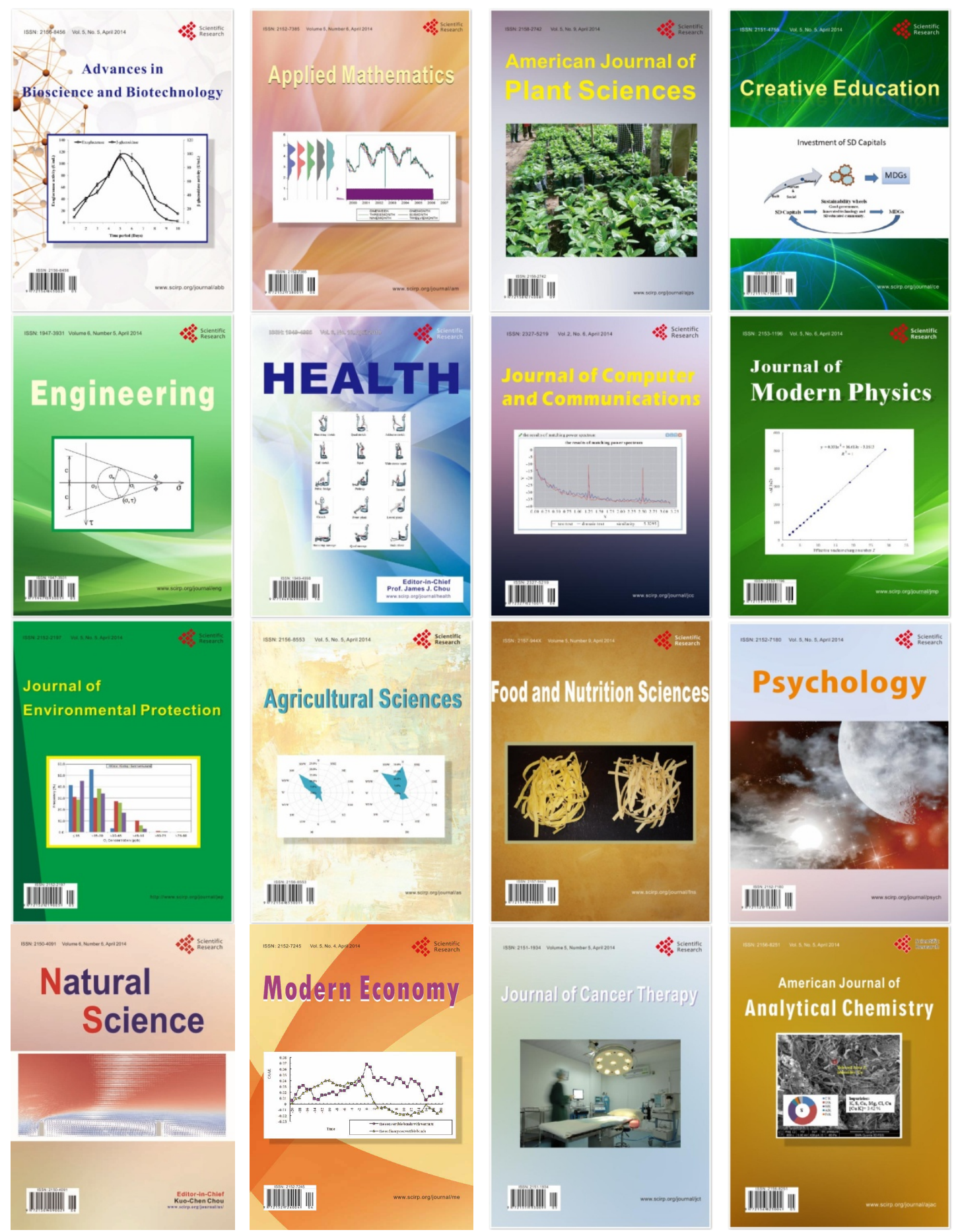